\title{
Knowledge Management Ecosystem based on Drupal platform for promoting the collaboration between Public Administrations
}

\author{
Alicia García-Holgado \\ GRIAL Research Group, \\ Research Institute for Educational Sciences, \\ University of Salamanca \\ Paseo de Canalejas 169, 37008 Salamanca, Spain \\ (+34) 923294500 ext. 3433 \\ aliciagh@usal.es
}

\author{
Francisco J. García-Peñalvo \\ GRIAL Research Group, \\ Research Institute for Educational Sciences, \\ University of Salamanca \\ Paseo de Canalejas 169, 37008 Salamanca, Spain \\ (+34) 923294500 ext. 1302 \\ fgarcia@usal.es
}

\begin{abstract}
The Spanish Public Administration has a decentralized structure organized in different levels: local government, regional government and central government. There is a huge amount of public institutions and organizations in each level and some of them share similar functions. Thus far there not existed a simple way to connect all the institutions in order to share their expertise and collaborate to improve the whole Administration. The knowledge management ecosystem for the Public Administration aims to address this problem by providing to the public employees a set of tools and information flows in order to promote the informal learning between them. This paper describes the technological ecosystem defined and implemented by the Research Group in InterAction and eLearning of the University of Salamanca in collaboration with the National Institute of Public Administration.
\end{abstract}

Categories and Subject Descriptors D.2.6 [Software Engineering]: Programming Environments $\rightarrow$ integrated environments.

D.2.13 [Software Engineering]: Reusable Software.

H.4.2 [Information Systems Applications] Type of Systems decision support.

H.5.3 [Information Interfaces and Presentation]: Group and Organization Interfaces.

\section{General Terms}

Management, Experimentation, Human Factors.

\section{Keywords}

Technological Ecosystem, eLearning Ecosystem, Information System, Drupal, Software Open Source, Knowledge Management, Public Administration.

\footnotetext{
Permission to make digital or hard copies of all or part of this work for personal or classroom use is granted without fee provided that copies are not made or distributed for profit or commercial advantage and that copies bear this notice and the full citation on the first page. To copy otherwise, or republish, to post on servers or to redistribute to lists, requires prior specific permission and/or a fee.
}

TEEM '14, October 01 - 03 2014, Salamanca, Spain.

Copyright is held by the owner/author(s). Publication rights licensed to ACM

ACM 978-1-4503-2896-8/14/10...\$15.00.

http://dx.doi.org/10.1145/2669711.2669964

\section{INTRODUCTION}

The Public Administration (PA) is composed by a set of public organizations, which are in charge of implementing government policies of a state.

Regardless of whether an institution is public or private, a large amount of knowledge is generated by their employees inside it and a correctly knowledge management is one of their main goals.

In the case of Spam, Public Administration is divided in three levels, the Central Government, the Regional Government and the Local Government. Due to this scheme, there are similar public organizations in each level and the knowledge generated could be shared between them in order to improve the whole system. Centralizing the knowledge management in the Spanish Public Administration is opposite to its decentralized nature. There are regional solutions mostly oriented to formal and non-formal learning [15-17] of their employees but does not exists a simple way to establish information flows between all public employees regardless their job position.

The Research Group in InterAction and eLearning (GRIAL) of the University of Salamanca [8] has huge expertise in the definition and development of technological solutions to support the knowledge management in both institutions and companies. Group expertise with technological ecosystems, some of them oriented to manage the informal learning as the European project "Tagging, Recognition and Acknowledgment of Informal Learning ExpeRiences (TRAILER)" $[6 ; 7 ; 9 ; 10]$ coupled with being part of a public organism as is the university, has provided the suitable context to collaborate with the Public Administration in order to develop a technological ecosystem to promote and support the knowledge management between the public employees.

This work presents an overview of the knowledge management ecosystem developed for the Public Administration. The paper is organizes as follow: Section 2 introduces the context and the main objectives; Section 3 describes the architecture and the technological decisions; finally Section 4 closes the paper with the main conclusion of this work and the future lines.

\section{CONTEXT AND OBJECTIVES}

One of the main problems in the Spanish Public Administration is the communication between public organisms. Their decentralized character entails there are organism with similar functions in each 


\section{Second International Conference on Technological Ecosystems for Enhancing Multiculturality - TEEM'14}

local or regional government. For example, each city hall can have different goals but they share similar purpose. In the case of the organisms in charge of the training and knowledge management of public employees, there are different schools, institutions, etc. in each region that have similar strategic plans but they not share courses, resources or expertise.

Some public institutions collaborate each other and exist formal protocols to connect them but there are not simple ways to connect people in order to share knowledge regardless the institution or region to which they belong.

During last years the Spanish government has implemented the Electronic Administration and has made a strong investment in the 2.0 approach and has fostered the use of Open Source software to cover their technological needs $[13 ; 14]$.

In this context, improving the communication to promote informal learning is one of the main goals of the Spanish Administration. In order to cover this need, the National Institute of Public Administration have included in their strategic plans the definition and implementation of a technological solution based on Open Source software to generate knowledge through the collaboration between public organizations. This Institute possesses a huge experience in knowledge management inside the Public Administration. We can find the following activities between its main tasks: (1) training and professional improvement for public employees; (2) recruitment into the Civil Service; and (3) promoting research and studies regarding government and the different levels on Public Administration from an interdisciplinary perspective.

The main objective implies a series of related sub-objectives:

- To create a space accessible from any public organization without compromising the security of the information.

- To provide procedures and tools with which the user can publish part of the knowledge generated in order to enforce the transparency law that allows public access to government information [B].

- To support the integration with other existing tools to achieve that all institutions and orgapisms are part of the project and collaborate in its evolution.

- To provide the user with information about other users with similar interest, promoting social learning and collaboration between the users of the system.

- To facilitate the decision making and the analysis of information flows in order to be able to improve the system and adapt it to the needs of the Public Administration.

- To establish the information flows and the mechanisms to support the four stages of the knowledge life cycle inside the Spanish Public Administration: creation, mobilization, diffusion and commoditization [2].

To achieve the aims described above, GRIAL research group, through the authors of this work, along with other companies with a huge expertise in knowledge management have collaborated with the National Institute of Public Administration in order to define and implement a technological ecosystem for enhancing the knowledge sharing between public employees.
The ecosystem has been designed using KISS ("Keep is simple, stupid") principle which states that most systems work best if they are kept simple rather than made complicated: getting knowledge from employees of each public organism; providing them an environment to process, in order to analyze and use it; returning at the last stage the generated knowledge to the Public Administrations (see Figure 1).

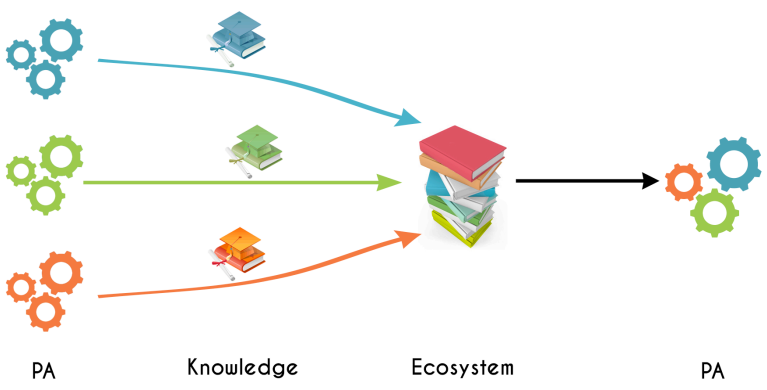

Figure 1. Collaboration between Public Administrations

\section{THE TECHNOLOGICAL ECOSYSTEM}

The National Institute of Public Administration has leaded the project from a theoretical point of view [1]. The analysis and definition of the system requirements has been realized by a group of experts composed by members of the Institute and experts on knowledge management from the business sector.

Moreover, GRIAL has participated as leader of the technological development. From the beginning of the project it has worked closely with the other team members in order to take the technological decisions.

Before the implementation of the ecosystem, the Institute already had some tools to knowledge management both internal and external.

First, a back-end tool, which provides the mechanisms to manage the information, supports the business processes and the internal information flows. This tool is based on a Liferay platform (http://www.liferay.com) connected with a document management system based on Alfresco (http://www.alfresco.com).

On the other hand, the Liferay platform mentioned above has a front-end that has been customized by the Information Technologies (IT) team of the Institute in order to provide a web portal with public information, from the training offer to the recruitment calls.

One of the main characteristics presented in a technological ecosystem must be the empowerment of reusable components, which means a benefit for the evolution of the different components [5]. In this context, the existing tools, both the web portal and the information system, have a high acceptation between their users and they work correctly so they have been included as components of the ecosystem.

The knowledge management ecosystem for the Public Administration is in a continuous evolution process. During last two years the ecosystem has evolved adapting to the definition elaborated by the experts and to the needs detected in the civil service. At the beginning, the ecosystem was composed by the tools described above. Later, a social network and a knowledge bank (BCI) were incorporated in order to change the knowledge management inside the whole Public Administration and promote 
the informal learning between workers. Currently, there is a fifth component, a repository of courses to enhancing the training in all schools and public institutions from the different Spanish regions.

The Figure 2 shows the architecture of the knowledge management ecosystem and the connections between the components. This is the result of the closely collaboration between all the team members, from the IT team of the National Institute of Public Administration to the graphic designers.

KNOULEDGE MANAGEMENT ECOSYSTEM FOR THE PUBLIC ADMINISTRATION

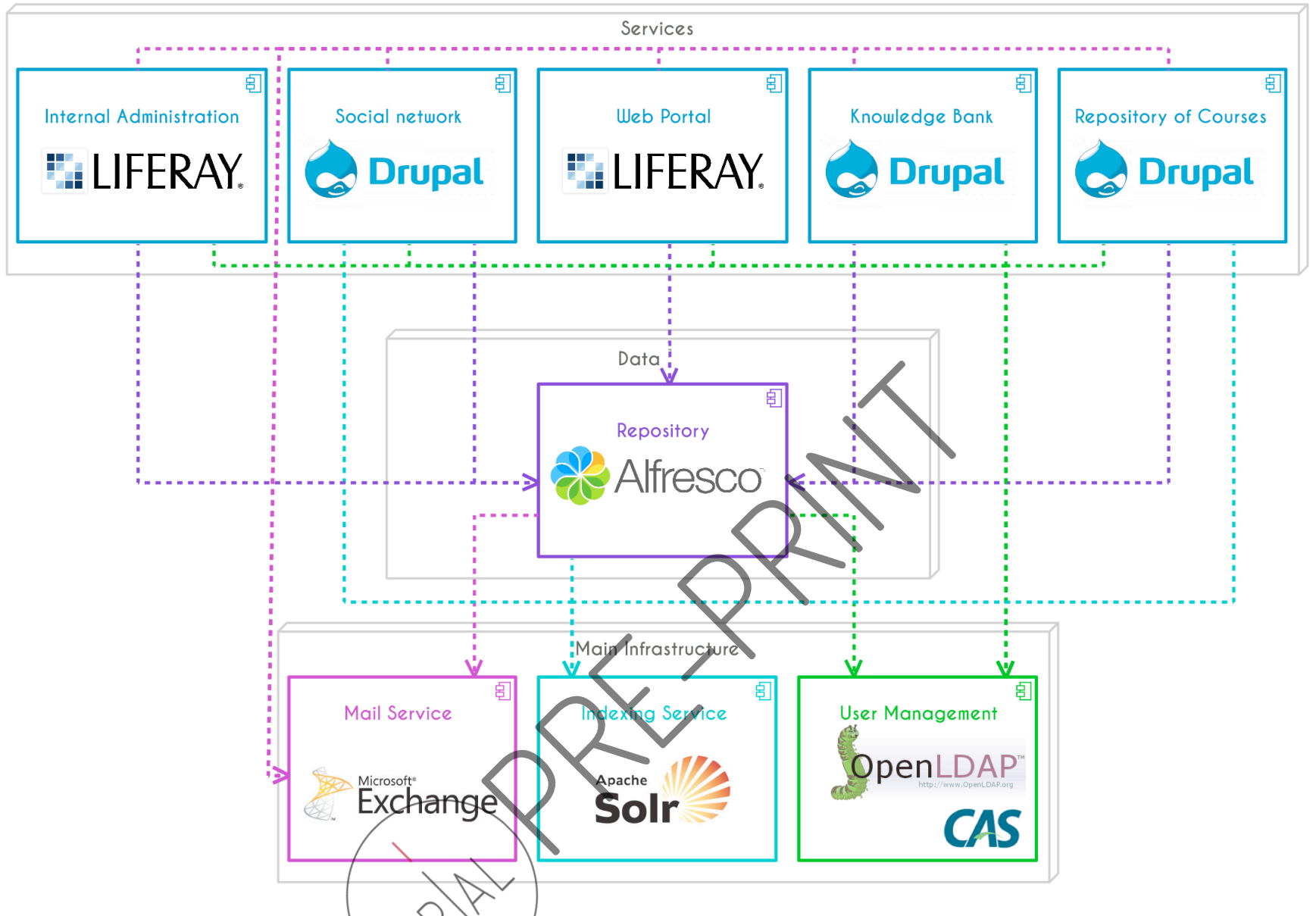

Figure 2. Architecture of the knowledge management ecosystem for the Public Administration

The architecture is divided in three layers based on the architectural proposal defined in previous works as result of the analysis of several technological ecosystems oriented to the knowledge management in different contexts [4;5]: infrastructure, data (static data management) and services.

First, the infrastructure layer contents the main services at internal level to make the system work properly. This layer includes three components. The mail server, based in Microsoft Exchange (http://office.microsoft.com/exchange), and the user management provided by an OpenLDAP server (http://www.openldap.org) linked with CAS (Central Authentication Service) (http://www.jasig.org/cas) are elements that exist before the ecosystem definition. The third component, an indexing server based on Apache Solr (http://lucene.apache.org/solr/), has been added in order to improve search results in the different applications.

The second layer encapsulates the management of the information that can be shared between the different services. Each service or application manages their own information but exists some kinds of information, as documents or images, which can be shared and used in different applications at the same time. This layer contents the repository, the document management system based on Alfresco. Besides the internal information flows, the repository has been adapted to support new applications.

The third layer is composed by the software components that provide the user-level services. Currently there are five components. The internal management system and the web portal to publish public information about the Institute has not required any development. Moreover, there are three services developed to complete the requirements of the ecosystem.

The social network for public employees provides a restricted space based on communities of practices which main goals is connect users with similar interests and generate knowledge from the interaction between them. The access to the social network is open to all workers from the Public Administration, regardless their institution, so the social network is the main entry point for 


\section{Second International Conference on Technological Ecosystems for Enhancing Multiculturality - TEEM'14}

people who want collaborate and benefit from the opportunities offered by a correct knowledge management.

On the other hand, the knowledge bank or BCI is the public interface to share the knowledge generated not only inside the ecosystem but also generated outside it. The access to the documents is divided in different levels, private, restricted and public documents.

Finally, the repository of courses provides a clear way to centralize the management of the training and the contents used by the institutes, schools, etc. from the different Spanish regions. The access to this repository is restricted to a few public employees dedicated to coordinate or implement the training for the Civil Service. This is due to it stores complete courses that can be deployed in different learning platforms.

Each component of the system has been developed independently although exist some information flows between them. In the case of GRIAL research group, it has coordinated the development of the social network and the repository of courses. The following sections outlines in more detail each of them.

\subsection{The Social Network for Public Employees}

One of the main characteristics of the technological ecosystem is the evolution and adaptation capabilities. For this reason, the methodologies used for developing technological ecosystems must be agile methodologies.

In the case of this social network the choice of an agile development methodology has allowed the evolution of the social network at the same time that the whole knowledge management ecosystem and the needs of their potential users.

The development has been divided into increments, which have facilitated the collaborative work involving all team members, from the end user to the developers. Each increment starts with an analysis of the previous iteration and the definition of the new requirements. The time frame for each increment is two to three months divided in several iterations in order to deploy the new features in the production environment as soon as possible. All iterations and increments has unit testing and there are acceptance testing at the end of each increment.

One of the most important technological decisions has been the choice of the technology over it develop the social network. The social network is a system with a high interaction level and a $3,000,000$ of potential users. It should manage a lot of information and should be accessible from any organisms. A Content Management System (CMS) provide a base to build online tools focused on manage information and support interaction between the users.

Currently there are three Open Source Content Management System (CMS) that have been established themselves as the leaders: WordPress (http://wordpress.org), Joomla (http://joomla.org) and Drupal (http://drupal.org). Although the three CMS have similar features, the social network is based on Drupal (release 7.x) because is the most technically advanced [11], with a powerful development framework, and it is the most recommended for community platform sites with multiple users [12] due to its own experience providing a space for working groups (https://groups.drupal.org).

The Drupal Community has a huge amount of modules to extend the functionality of its core. The most important extensions installed to build the social network are:
- Organic Groups $(O G)$ to provide support to the practices communities. This module is used by Drupal in its groups.

- Forum to integrate the use of forums within the communities, the $O G$ forum $D 7$ is used, which allows the association of forums to a community and the management of visibility, participation and permissions for the specific members of a community.

- $\quad$ Privatemsg and User Relationships to promote private collaborations between users with similar objectives in order to promote the social learning.

- $\quad$ Profile 2 to define a complete professional profile.

- Calendar, iCalcreator library (http://kigkonsult.se/iCalcreator/) and Date to create a events management tool with two levels, one for the events related with the practices communities and other for global events.

- Wysiwyg and CKEditor library (http://ckeditor.com) to provide a friendly editor to the end users.

- Views and Panels to control and configure the structure of the interface and the visualization of all the information shown in the social network.

Rules and Flag to build the notifications system in order to allow users subscribe to the activity of their communities.

SMTP to use the mail server located in the infrastructure layer of the knowledge management ecosystem.

- $\quad C A S$ and Lightweight Directory Access Protocol $(L D A P)$ to integrate the social network with the user management system of the National Institute of Public Administration.

- $\quad$ Apache Solr Search to integrate the social network with the indexing service based on Solr that is located in the infrastructure layer of the ecosystem.

As part of a technology ecosystem, there is a high degree of interoperability with other components of the ecosystem. In this sense, three new modules have been development for this project.

First, the integration with users management system of the National Institute of Public Administration, which combines an authentication server (CAS) and an users management server (OpenLDAP). Although there is integration between Drupal and CAS, the module does not support the creation of new users from the social network to the CAS server. The IT team from the Institute has developed a REST interface for their CAS server in order to provide the required methods to create users from Drupal. On the other hand, GRIAL has developed a client to use the REST services and process the creation of new users in the social network.

The social network has integrated with the knowledge bank too. The BCI provides a full support to the storage and sharing of knowledge both inside and outside the Public Administration. The main objective is establishing an information flow between the social network and the $\mathrm{BCI}$ in both directions: from the social network to the BCI in order to save and share the knowledge generated inside the practices communities; and from BCI to the social network in order to provide access to the documents stored 
in the BCI through a search interface. This integration has been developed in collaboration with the BCI developers in order to understand the tool and integrate it reducing the dependencies between both systems.

The BCI is based on Drupal too but the bulk of the work falls in the document management system based on Alfresco, other of the ecosystem components. For this reason, the information flow between the social network and the BCI is supported by integration with Alfresco through a web services interface.

Finally, we have developed a complex module to integrate the social network with external organizations that they not have their own social tool and with other social networks that are used in some public organisms. The module allows integrate new institutions through a simple but powerful administration interface that can be used by any user with the correct permissions.

\subsection{The repository of courses}

Both the social network and the knowledge bank are based on Drupal 7 as technological support. The repository of courses, as last component added to the ecosystem, is based on Drupal too in order to reduce the maintenance of the three components and facilitate future integrations.

Same as the social network, the repository of courses has been developed using an agile methodology even though is a smaller project.

In this case, the development has been divided in iterations of two or three weeks. Each iteration has ended with a testing phase such that the results have been the inputs for the next iteration.

The repository of courses is integrated with the mail server, the users management system and the indexing service of the knowledge management ecosystem in the same way that the social network with the SMTP, Apache Solr Search, CAS and Lightweight Directory Access Protocol (LDAP) modules

For this project, one of the modules developed to the social network has been adapted in order to support the integration with the user management system and the administration interface for creating new users. In the case of the social network, the users can register without the validation of a administrator. The repository of courses is restricted to a few users with a specific profile inside the Public Administration so it has to be controtied.

The roles and permissions system is complex and has been necessary develop a module to modify the users management provided by Drupal. The authenticated users are classified in four roles. On one hand, two kinds of administrators, one general and one for each organization interested in collaborate with the repository. On the other hand, two normal users, one that only can search and consult courses and other that can publish new courses.

The module developed adapts the system to rewrite some functions of the administrators of public organism. This kind of users only can create users and courses belonging to his organism.

\section{CONCLUSION}

The knowledge generated inside the Spanish Public Administration is fragmented between the huge amount of public organisms that compose it, from the local government to the central government. The communication channels between public organisms and employees are poor, there are formal protocols and some tools to establish contact with each others but does not exist a tool that connect them in an informal way in order to improve the knowledge management and enhancing the synergies inside the Civil Service.

The knowledge management ecosystem for promote the informal learning described in this work represents a strong change in a decentralized organization as is the Spanish Public Administration.

The heterogeneity of the team and the choice of an agile methodology have allowed create a powerful ecosystem with a high flexibility and adaptability to the needs of the Public Administration. The use of a Open Source software and the integration with services provided by the National Institute of the Public Administration has allowed develop the ecosystem in a short time frame.

Both the social network and the repository of courses have a high acceptation between the public employees. The participation of GRIAL research group since its beginning has provide a real context to apply the know-how acquired by the group in previous experiences and expand its knowledge on technological ecosystems and the knowledge management in the Public Administration context

\section{ACKNOWHEDGMENTS}

This research work is made within University of Salamanca PhD Programme on Education in the Knowledge Society scope.

Authors would like to thank their partners at Research Group in InterAction and eLearning (GRIAL) http://grial.usal.es and the University Institute of Education Sciences (IUCE) at the University of Salamanca http://iuce.usal.es for their contributions and support.

\section{REFERENCES}

[1] Arenilla Sáez, M., 2014. Conocimiento transformador y talento público. El caso del INAP. National Institute of Public Administration, Madrid, Spain.

[2] Birkinshaw, J., Sheehan, T., and Team, L.Y., 2003. Managing the Knowledge Life Cycle. Cambridge MA.

[3] España, 2013. Ley 19/2013, de 9 de diciembre, de transparencia, acceso a la información pública y buen gobierno Boletín Oficial del Estado.

[4] García Holgado, A. and García Peñalvo, F.J., 2013. Análisis de integración de soluciones basadas en software como servicio para la implantación de ecosistemas tecnológicos corporativos. In Avances en Informática y Automática. Séptimo Workshop, J. CruzBenito, A. García-Holgado, S. García-Sánchez, D. Hernández-Alfageme, M. Navarro-Cáceres and R. Vega-Ruiz Eds. Departamento de Informática y Automática de la Universidad de Salamanca, Salamanca, 55-72.

[5] García-Holgado, A. and García-Peñalvo, F.J., 2013. The evolution of the technological ecosystems: an architectural proposal to enhancing learning processes. In Proceedings of the Proceedings of the First International Conference on Technological Ecosystem for Enhancing Multiculturality (Salamanca, Spain2013), ACM, 2536623, 565-571. DOI= http://dx.doi.org/10.1145/2536536.2536623. 
García-Peñalvo, F.J., Conde-González, M.Á., Zangrando, V., García-Holgado, A., Seoane Pardo, A.M., Alier, M., Galanis, N., Brouns, F., Vogten, H., Griffiths, D., Mykowska, A., Ribeiro Alves, G., and Minović, M., 2013. TRAILER project (Tagging, recognition, acknowledgment of informal learning experiences). A Methodology to make visible learners' informal learning activities to the institutions. Journal of Universal Computer Science 19, 11, 1661-1683.

[7] García-Peñalvo, F.J., Johnson, M., Ribeiro Alves, G., and Minovic, M., 2014. Informal learning recognition through a cloud ecosystem. Future Generation Computer Systems 32, 282-294. DOI= http://dx.doi.org/http://dx.doi.org/10.1016/j.future.2013. 08.004 .

[8] García-Peñalvo, F.J., Rodríguez Conde, M.J., Seoane, A.M., Conde, M.Á., Zangrando, V., and GarcíaHolgado, A., 2012. GRIAL (GRupo de investigación en InterAcción y eLearning), USAL. Revista Iberoamericana de Informática Educativa, 15, 85-94.

[9] García-Peñalvo, F.J., Zangrando, V., García-Holgado, A., Conde González, M.A., Seoane-Pardo, A.M., Alier, M., Galanis, N., López, J., Janssen, J., Brouns, F., Finders, A., Berlanga, A., Sloep, P., Griffiths, D., Johnson, M., Waszkiewicz, E., Mykowska, A., Minovic, M., Milovanovic, M., Marques, M.A., Viegas, M.C., and Alves, G.R., 2013. A Tool to Aid Institutions Recognize Their Employees Competences Acquired by Informal Learning. In Scaling up Learning for Sustained Impact, D. Hernández-Leo, T. Ley, R. Klamma and A. Harrer Eds. Springer Berlin Heidelberg, 552-555. DOI= http://dx.doi.org/10.1007/978-3-642-40814-4 56.
[10] García-Peñalvo, F.J., Zangrando, V., García-Holgado, A., Conde-González, M.Á., Seoane Pardo, A.M., Alier, M., Janssen, J., Griffiths, D., Mykowska, A., and Ribeiro Alves, G., 2012. TRAILER project overview: Tagging, recognition and acknowledgment of informal learning experiences. In Computers in Education (SIIE), 2012 International Symposium on IEEE, 1-6.

[11] Mening, R., 2014. WordPress vs Joomla vs Drupal + CMS "comparison chart".

[12] Rackspace, 2013. CMS Comparison: Drupal, Joomla and Wordpress.

[13] Ramsamy, P., 2011. Criteria for adopting open source software in Public Administrations. CENATIC, Badajoz, Spain.

[14] Trejo Pulido, A., Domínguez Dorado, M., and Ramsamy, P., 2011. Open source software in public organisations of the Spanish government. 2011. CENATIC, Badajoz, Spain.

[15] Werquin, P., 2007. Terms, concepts and models for analysing the value of recognition programmes. Organisation for Economic Co-operation and Development.

[16] Werquin P., 2008. Recognition of non-formal and informal learning in OECD countries:A very good idea in jeopardy? Lifelong Learning in Europe 2008, 3, 4249.

[17] Werquin, P., 2010. Recognising Non-Formal and Informal Learning: Outcomes, Policies and Practices.

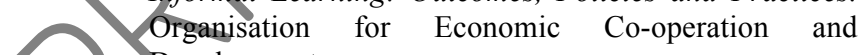

